\title{
Characterization and Identification of Electrical Customers Through the Use of Self-Organizing Maps and Daily Load Parameters
}

\author{
Sergio Valero Verdú, Mario Ortiz García, Francisco J. García Franco, Nuria Encinas, \\ Antonio Gabaldón Marín, Member, IEEE, Angel Molina and Emilio Gómez Lázaro
}

\begin{abstract}
This paper shows the capacity of modern computational techniques such as the self-organizing map (SOM) as a methodology to achieve the classification of the electrical customers in a commercial or geographical area. This approach allows to extract the pattern of customer behavior from historic load demand series. Several ways of data analysis from load curves can be used to get different input data to "feed" the neural network. In this work, we propose two methods to improve customer clustering: the use of frequency-based indices and the use of the hourly load curve. Results of a case study developed on a set of different spanish customers and a comparison between the two approachs proposed here are presented.
\end{abstract}

Index Terms-. Artificial Neuronal Networks, Electrical Customer Segmentation, Electricity Markets, Time-Frequency Analysis, Customer Aggregation.

\section{INTRODUCTION}

$I^{2}$ new liberalized markets, as we have in the great majority of the industrialized countries, the electrical customers have the opportunity of choosing between several commercializers and thus, the possibility to access to new products and services from Supply-Side [1]. For this reason, energy commercializers and aggregators are now more and more interested in the development of new suitable strategies and products oriented to Demand-Side -customers- in order to achieve the best service to be offered to each different user or to find new market opportunities -for example through Load Trade Services, LTS-.

In this way, supply-side actors in the liberalized electricity market scenario -aggregators, commercializers or distributorsneed to model and describe precisely the customer demand to evaluate the potential and feasibility of a specific product or policy -for example Real-Time tariffs or Demand-Side

S.Valero and M. Ortiz are with the División de Ingeniería Eléctrica, Departamento de Ingeniería de Sistemas Industriales, Universidad Miguel Hernández, Elche, Spain (e-mails: svalero@umh.es, mortiz@umh.es).

F. García Franco and Nuria Encinas are with the Institute of Energy Engineering (IIE), Universidad Politécnica de Valencia, 46071 Valencia, Spain

A. Gabaldón, A. Molina and E. Gómez are with the Departamento de Ingenieria Electrica, Universidad Politécnica de Cartagena, Murcia, Spain (emails: antonio.gabaldon@upct.es, angel.molina@upct.es).
Bidding policies-. This paper describes the first step: to define a methodology to classify customer segments on the basis of the electrical behavior of customers and perhaps, if needed, in some non-electrical parameters such as the type of economical activity -NACE codes-.

This paper presents a research work demonstrating the potential of a well known tool: the Kohonen self-organizing map (SOM). So, the SOM approach can be easily used as a management tool for the electrical customer classification through the treatment of real daily demand curves. Information on customer demand is available by means of electronic demand watt-hour meters, which have been extensively used by utilities in the last decade.

The study is based on real data from several spanish customer sectors in two geographical areas, such as University buildings, residential zones and medium size industries. The demand curves are defined by active power points measured every 15 minutes and the data have been treated in several ways in order to feed the SOM network.

The paper is organized in six sections. In Section II some customer clustering techniques previously developed in the bibliography are reviewed. Section III presents a brief description and characteristics of SOM. Characteristics of customer reference population used to SOM training, the load data conditioning and the definition of time and frequency indices are presented in Section IV. Subsequently various SOM maps are obtained for each set of indices, the details are described in Section V. In Section VI is analyzed the performance of each classification criteria, using a new set of load curves different from the one used for SOM training. Finally some conclusions and future works are stated in Section VII.

\section{A REVIEW OF CUSTOMER CLASSIFICATION TECHNIQUES}

There are a lot of techniques and tools that can be used for studying customers electrical consumption. The target is to group customers with similar load profiles in coherent clusters that can be used for different purposes such as billing, utilitycustomer relationship, marketing,... A review of these methods is given in the present section.

Paying attention to the data used for classification, we can talk of time domain approaches or frequency domain approaches [3]. As for the parameters or features that the 
analysis is based on, it can be distinguish between intrinsic, extrinsic or hybrid analysis [4]. The first of them is based on the use of shape features -those obtained from load diagram-, while intrinsic analysis make use of external features so called predictor attributes, such as weather or economics variables. Finally, hybrid analysis is the most typical and complete approach. It consist of a first phase of extrinsic analysis to obtain more easy to handle groups to which is applied a intrinsic phase. In this way more information is taken into account and customers relations can be deduced whereas only using intrinsic analysis this information could be overlooked.

A high division of classification techniques can be as follow: clustering algorithms, statistics, neural approaches and fuzzy systems as well as different combinations of them.

\section{A. Clustering Algorithms.}

Classic clustering algorithms [4] are divided into:

One step clustering. Profiles are presented one by one and are assigned to an existing cluster if distance to this is lower than a determined threshold. Otherwise a new cluster is established.

Binary splitting algorithm. At the beginning there are two clusters; one containing all profiles and one empty. Profile that most increase or least decrease the distance between the two clusters is passed from first cluster to second and the new distance is recorded. At the end, the two clusters with the between longer distance are chosen. A new binary division process is applied to the resulting algorithm and the methodology continue until a number of cluster determined is reached.

Iterative Join-Two algorithm. Initially there are as much clusters as profiles. In each iteration the distance between each pair of clusters is computed. The clusters whose distance is the lowest are merged into a new cluster. Distances are recomputed and process continues until the desired number of clusters is reached.

Exhaustive binary search. The distance between each possible pair of clusters containing all of the profiles is computed. The winner clustering is the one that produces the greatest value. Applying the process in a recursive form it can be reached a fixed number of clusters.

\section{Statistics}

Better than classification techniques, statistics must be seen as useful tool for working with previous classified data. As example, we can treat all profiles belonging to a class and obtain a statistical distribution that explain customers consumption by means of average and deviation profiles [5], [6], [7]. In other cases, statistics are presented as tools used in the own classification process. In this way, it permits to study between and within-cluster scatter due to a determined classification [4]. Other common use given to statistical tools is the correlation analysis between consumption and different variables like temperature [6], to obtain models that explain that demand.

\section{B. Neural Approaches}

For some time to now Artificial Neural Networks (ANN), [8], have been proven to be suitable systems for load modelling where others systems where not accurate. These systems present the disadvantage of a training phase needed to make a correct classification, but once it is accomplished, the network is able to classify load profiles with a very low error rate. Particularly, the most suitable network for load profiles classification is the Self-Organizing Map (SOM) [2], [3], [9]. An introduction to the basics as well as detailed applications and conclusions are given for this kind of net in this paper.

\section{Fuzzy Classification}

Fuzzy methods entail work with data collections which boundaries are not clearly defined. Fuzzy techniques are based on the use of the so-called membership functions which try to measure the affinity a sample of data has as regards a cluster. In other words, membership functions give us the suitability of assigning a sample to a cluster better than to other. Among the different fuzzy methods, the most known is c-means proposed by Bezdek [10], or k-means proposed by De Gruiter \& McBartney [11]. The method consist on the minimisation of an objective function representing the distance between a given sample of data and a cluster centre. This distance is weighted by a membership function that gives a relation for the distance of the data to classify to the cluster studied and the distance between all existing clusters and the centroid of the cluster as regards affinity is evaluated. Second of the two proposed methods modify the objective function to take into account outliers outside the main body of data.

\section{Combining Methods}

Processes of classification of electricity customers are not usually based only in a single method. There are a lot of examples in the bibliography where two methods are applied to the same data group to compare their suitability [8], [9], [14]. In other cases methods are employed together to complement each other: in [4] is exposed the use of different clustering algorithm as the process moves forwards in an adaptative methodology, in [12] a fuzzy technique is employed with help of statistical parameters, in [13] data are grouped by means of a SOM and then fuzzy techniques are used to distinguish the clusters. These combined uses in addition to the large quantity of features that can be used to characterize the customer give as result a wide range of methodologies to deal with electricity customers classification.

\section{SELF ORGANIZING MAPS}

The successful application of Artificial Neural Networks to solve a wide set of Electrical Power System problems and, specifically the suggested use of the SOM maps for applications such as short-term load forecasting, detection of similar load behaviour or anomalous data detection, move the authors of this work to the idea to evaluate the benefits of 
improving SOM training and clustering criteria based not only on load shape factors but in other alternative indices.

This methodology, the SOM maps, was introduced by Teuvo Kohonen two decades ago [2]. These networks are an unsupervised ANN that performs a clustering analysis of an ndimensional input data vector. The SOM map is defined by a pre-selected grid of units (two dimensional in this case) which forms a selective grid for each input data.

Through the learning algorithm -inspired in biological perception mechanisms- the SOM recognises very well patterns in a set of $\mathrm{n}$-dimensional input data -in our case some indices extracted from the daily load curve demanded by our customers-. Besides, it holds the topological preservation property. This implies that similar input data are grouped together in the same region of the two-dimensional map -i.e., SOM map transforms the $\mathrm{n}$-dimensional space of the input data vector indices into the two-dimensional grid of the map-. This property is used in next paragraphs in order to classify customer segments -separate areas in the grid, so called bubbles activity- during the training process. This property implies an important improvement from the traditional clustering approach, due to the fact that a simple visual inspection of the data peculiarities is allowed from the SOM map.

\section{APPLICATION TO CUSTOMER SEgMENTATION}

\section{A. Case Study}

The load daily curves conforming the set of measurements for training and evaluation of SOM maps are extracted from different tests made from 1995 up to now in several customers for Demand-Side evaluation purposes in Spain. This set contains a mix of industrial, institutional and small residential loads -in this last case the load is aggregated in the high voltage side of a distribution transformer centre, CT-. The annual peak load varies from two hundred kilowatts -for the smaller user- to $10 \mathrm{MW}$ for the greater customer demand.

Table I shows: the individual customers selected from different geographical areas to perform training (U1, U2,..), the mask associated to daily load curves -a number of mask for all the load curves for a given customer-, the number of load curves considered for each customer, and the a priori customer classification according to its activity -institutional, residential, industrial-. So the global number of n-dimensional vectors used for training SOM was 327, each one corresponding to a demand curve.

TABLE I

CUSTOMER SPECTRUM FOR SOM TRAINING

\begin{tabular}{|c|c|c|c|}
\hline Customer & Label & $\begin{array}{l}\mathbf{N}^{\circ} \text { of input } \\
\text { data } \\
\text { vectors }\end{array}$ & Customer activity \\
\hline U1 & 1 & 22 & University \\
\hline U2 & 2 & 16 & University \\
\hline I1 & 3 & 15 & Industry \\
\hline I2 & 4 & 15 & Industry \\
\hline
\end{tabular}

\begin{tabular}{|c|c|c|c|}
\hline R1 & 5 & 6 & Residential CT \\
\hline R2 & 6 & 5 & Residential CT \\
\hline R3 & 7 & 5 & Residential CT \\
\hline R4 & 8 & 5 & Residential CT \\
\hline U3 & 9 & 8 & University \\
\hline U4 & 10 & 7 & University \\
\hline U5 & 11 & 20 & University \\
\hline U6 & 12 & 20 & University \\
\hline U7 & 13 & 20 & University \\
\hline U8 & 14 & 20 & University \\
\hline U9 & 15 & 20 & University \\
\hline U10 & 16 & 22 & University \\
\hline I3 & 17 & 30 & Industry \\
\hline I4 & 18 & 22 & Industry \\
\hline R6 & 19 & 24 & Residential CT \\
\hline R7 & 20 & 25 & Residential CT \\
\hline
\end{tabular}

\section{B. Data Processing And Conditioning.}

Daily load curves have a different behaviour for each user, peak power values and pacer trigger ratios -for data acquisition in conventional databases- are quite different too. To compare these curves from different types of customers and measurement facilities is necessary to follow some data conditioning procedure before the SOM was "fed" with load curves. In this paper the following three-step protocol was used. The first step was to filter anomalous data in load curves -and anomalous days such are for example holiday periods- from curves and databases. Then, to standardize data sampling ratio -for convenience a rate of 96 samples a day was chosen-, and finally the demand curves were normalized the base selected was the peak customer demand-. This last step is convenient not only to compare customers of the same segment but different size when load shape factors are used; it is necessary when we try to obtain and compare frequencybased indices -load curve harmonics for different customers-.

\section{Time Domain Indices}

\section{1) Load Shape Factors:}

In order to study daily load profiles, it is useful to divide the daily period in different time intervals. Using normalized active power values obtained from that periods, several characteristic shape factors have been calculated. In this paper nine factors -shown in Table II- are used: first six shape factors are based in those reported by Chicco [3]; three more shape factors have been added to complete the study.

TABLE II

SHAPE FACTORS USED IN CUSTOMERS CLASSIFICATION

\begin{tabular}{|c|c|}
\hline Notation & Definition \\
\hline $\mathrm{f}_{1}$ & $P_{a v, \text { day }} / P_{\max , \text { day }}$ \\
\hline $\mathrm{f}_{2}$ & $P_{a v, \text { daylight }} / P_{\max , \text { daylight }}$ \\
\hline $\mathrm{f}_{3}$ & $P_{\min , \text { day }} / P_{a v, \text { day }}$ \\
\hline $\mathrm{f}_{4}$ & $1 / 3 \cdot\left(P_{a v, \text { night }} / P_{a v, \text { day }}\right)$ \\
\hline $\mathrm{f}_{5}$ & $1 / 5 \cdot\left(P_{a v, \text { lunchtime }} / P_{a v, \text { daylight }}\right)$ \\
\hline
\end{tabular}




\begin{tabular}{|c|c|}
\hline $\mathrm{f}_{6}$ & $P_{\text {min,daylight }} / P_{a v, \text { daylight }}$ \\
\hline $\mathrm{f}_{7}$ & $P_{a v, \text {,ight }} / P_{a v, \text { daylight }}$ \\
\hline $\mathrm{f}_{8}$ & $\frac{1}{5} \cdot\left(P_{\max , \text { daylight }} / P_{\max , \text { day }}\right)$ \\
\hline $\mathrm{f}_{9}$ & $P_{\min , \text { day }} / P_{\min , \text { daylight }}$ \\
\hline
\end{tabular}

Time periods considered and their subsequent representative sub-indices are as follows: day -is referred to the full 24 hours day time period-, daylight -from 7:30 to 18:30-, night -from 22:00 to 7:30-, lunchtime -from 13:30 to 15:30-. Because of the different relative importance of the factors some weights have been applied. As example, $f_{8}$ factor is affected by a $1 / 5$ weight because maximum demand in daylight period is coincident with that for full day interval for the most of the consumers, so factor takes a unit value.

2) Hourly Load Profiles:

Complete hourly load profiles are used instead of shape factors for classification purposes. Starting from 96 normalized values and using linear interpolation 24 consumption values are obtained representing per unit daily profile.

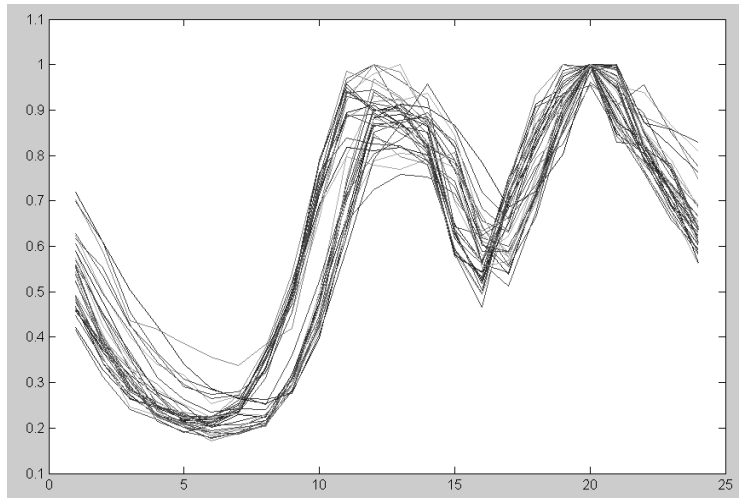

Fig. 1. Hourly Load Profile With 24 Normalized Values

\section{Frequency Domain Indices}

Indices are calculated via DFT - Discrete Fourier Transform - interpolation. First DFT is applied to obtain a continuous load curve in frequency domain. The curve is sampled with a 15 minutes fixed ratio so 96 points are taken for a day.

Following four different variables groups taken as inputs for the neural network are exposed.

1) 48 Harmonics Amplitude:

Input data are formed by the sum of all the load profile points and the first 47 harmonic modules. As per unit values are used, first data - the sum of all modules - is coincident with load factor that gives information about how smooth the consumption profile is. Harmonics complete information about the shape of the load curve.

2) 24 Harmonics Amplitude:

Similar to the previous calculation but using only 23 harmonics and the first term of DFT -data sum-.

3) 23 Harmonics Amplitude:

In this case the first value of DFT is not considered.

4) 10 Complex Coefficient.

Input data are formed by the sum, and the first 10 harmonic modules and angles.

\section{SOM TRAINING}

The six trainings, one for different treatment, have been done under the same simulation procedure. A neural network of $21 \times 21$ cells has been selected with a primary training of 8000 steps and a secondary one of 4000 steps. Due to the number of input data vectors, 327 , the size of the net, 441 cells, allows a certain cluster separation and aggregation of similar customers.

\section{A. Time Domain Training}

\section{1) Training with 9 shape factors:}

After simulating all the customers with their characteristic labels in a $21 \times 21$ cell map, with a primary and secondary training of 8000 and 4000 steps, the following cluster classification has been achieved.

$$
\text { Labels }
$$

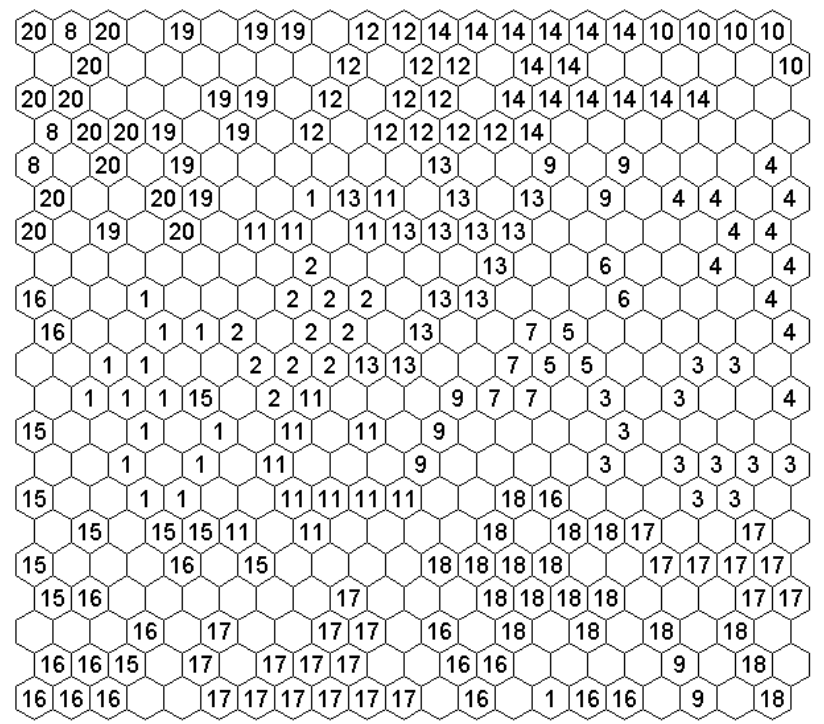

Fig. 2. 9 Shape Factors Training

The clustering of similar customers is very high. Labels 19 and 20 -residential customers- are placed in the same area, as happens with customer labels 1 and 2, both universities.

\section{2) Training with Hourly Load Profile:}

The next map is obtained after training the SOM with the data of the active power daily load curve normalized and reduced to 24 points. With this treatment we are taking directly the shape of the load curve as input data vectors. 


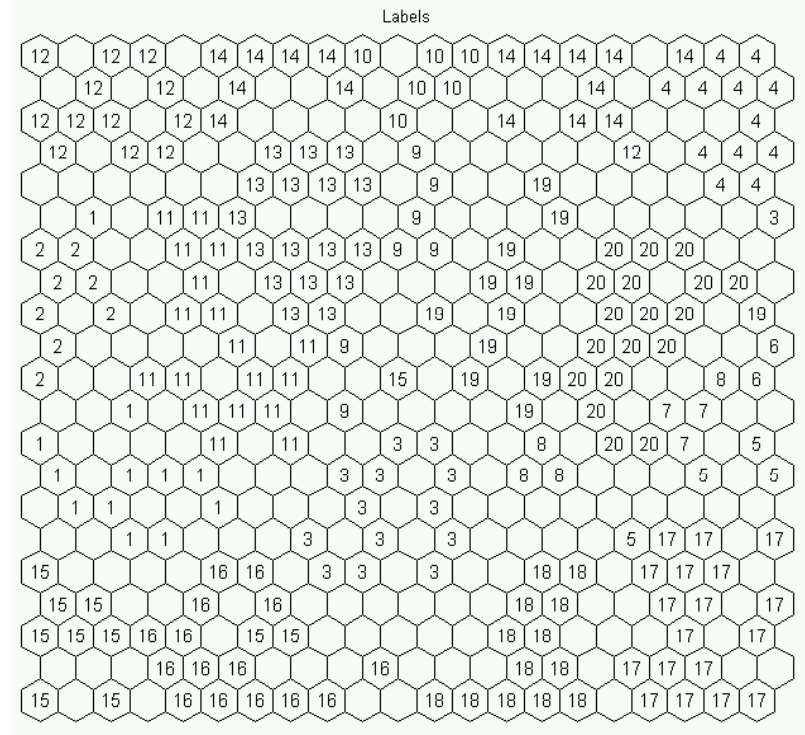

Fig. 3. Hourly Load Profile Training

This training provides the best cluster classification. The map shows clearly different zones, but placing similar customers near. Although 17 and 18 labels represent different customers, both are small industries and appear in the same zone. Something similar happens with labels 5, 6, 7, 8, 19 and 20, all different customers but representing the same demand segment -small residential users-.

\section{B. Frequency Domain Training}

1) 48 Harmonics Amplitude Training:

The map after training the SOM with the amplitude of the first 47 harmonics and the load factor of daily load curves is shown in figure 4.

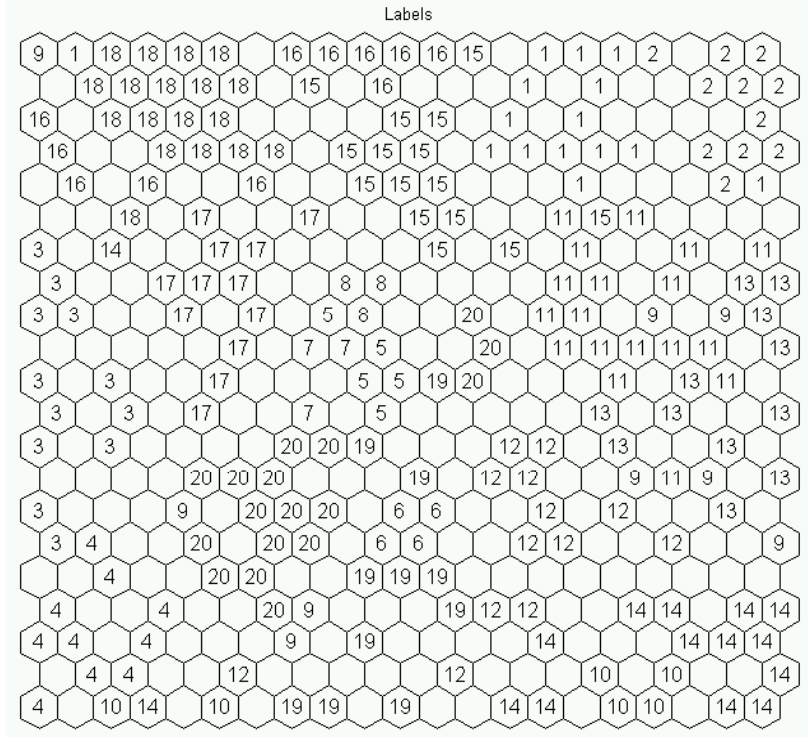

Fig. 4. 48 Harmonics Amplitude Training

Certain customers present a good classification, for instance labels 1 and 2 -both universities- and labels 17 and 18 -small industries- appear in very closed areas.

2) 23 Harmonics Amplitude Training:

The resulting map for the 23 harmonics amplitude training is shown in the figure 5 .

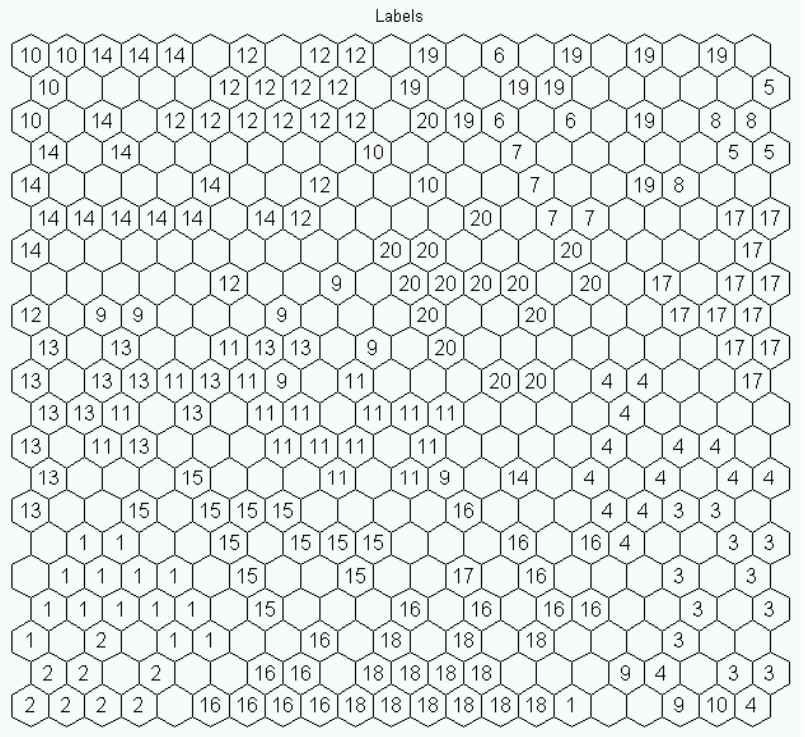

Fig. 5. 23 Harmonics Amplitude Training

The grouping in this treatment is good enough and the zone clustering is more clear in comparison with 9 factors training case.

3) 24 Harmonics Amplitude Training:

The SOM training using the 23 harmonics amplitude and load factor term is presented in the figure 6 .

Labels

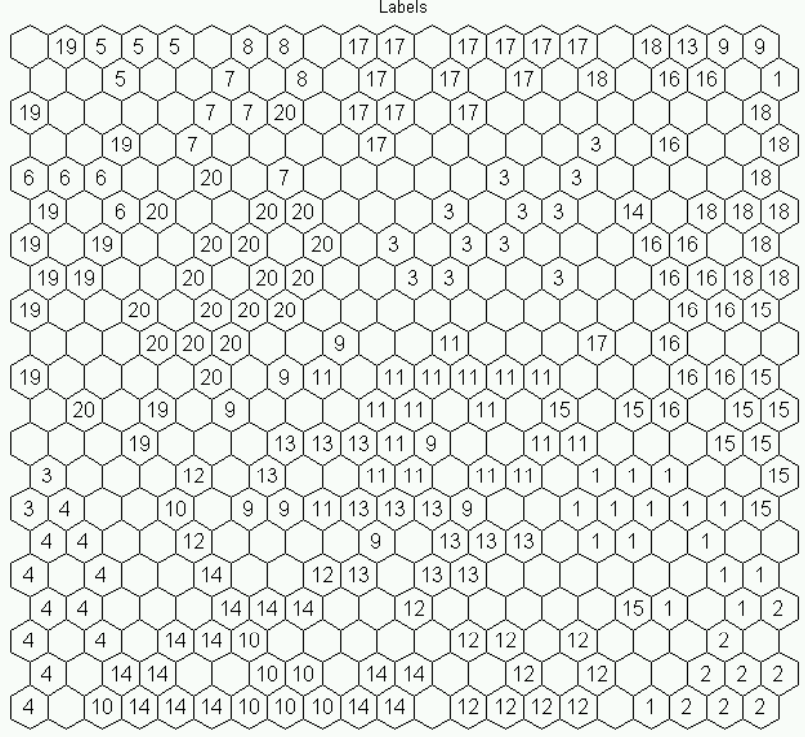

Fig. 6. 24 Harmonic Amplitude Training

The map fails because certain labels are located in other label zones. For example in the up-right zone labels 1, 9 and 13 appear in the segment defined by labels 17 and 18 .

4) Complex Coefficients Training:

21 value have been used in this training, the load factor of the daily load curve and the first 10 harmonics amplitude and angles. 


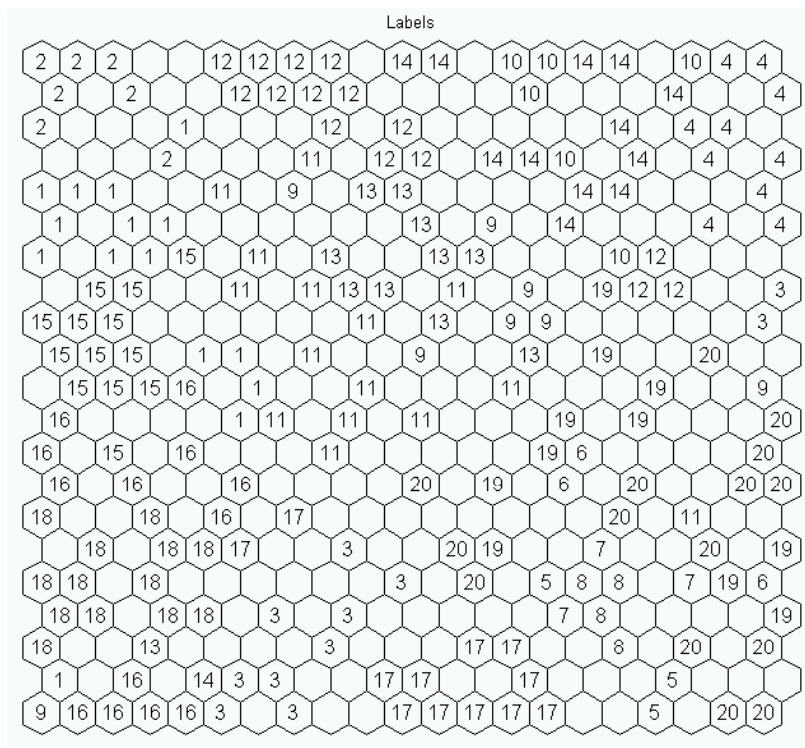

Fig. 7. Complex Coeficients Training

The map zones are not so clear as in the other treatments. For example, a customer labelled with 1 appears in two different zones corresponding to labels 17 and 18, and moreover some customer-label 3-is placed in the same area.

\section{APPLICATIONS AND RESUltS}

\section{A. Customer Segmentation Criteria}

Through a training map is possible to identify zones of customers with similar characteristics [8]. Using the best map obtained in the previous simulations, the Hourly Load Profile, the 20 customers simulated can be classified in five different zones: University $-1,2,9,10,11,12,13,14,15$ and 16-, Residential -5, 6, 7, 8, 19 and 20-, Medium Industry -3, 4- and Small Industry -17 and 18 - (see figure 8 ).

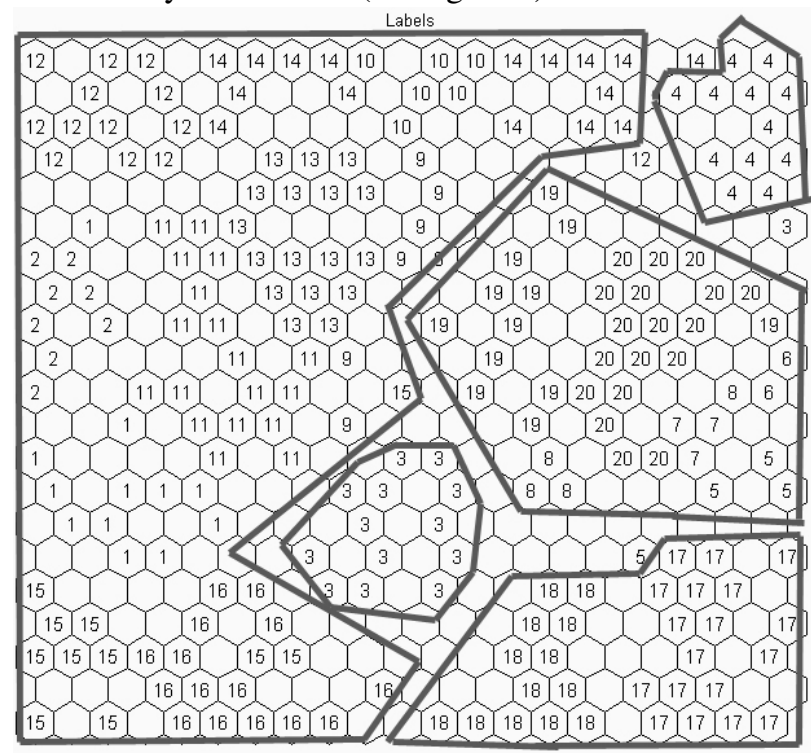

Fig. 8. Customer Aggregates

\section{B. Index Matching Performance}

In this paragraph we will evaluate the SOM performance for customer segmentation. Three new customers -an university, a small industry, and a residential CT- have been used to test the SOM adequacy for customer classification. The target is to get for each data input the more similar cell.

TABLE III

COSTUMER TESTING

\begin{tabular}{|c|c|c|}
\hline Customer & $\begin{array}{c}\text { Number of entry data available } \\
\text { (number of load curves) }\end{array}$ & Type of customer \\
\hline University A & 16 & University \\
\hline Industry B & 21 & Small Industry \\
\hline Residential C & 31 & Residential CT \\
\hline
\end{tabular}

\section{1) University A, testing}

The number of daily load curves used for testing purposed was 16. The adequacy of SOM is stated in table IV.

TABLE IV

RESULTS OF UNIVERSITY A TESTING

\begin{tabular}{|c|c|c|c|}
\hline Training data & Labels identified & $\begin{array}{l}\text { Kind of customer } \\
\text { identified }(\%)\end{array}$ & $\begin{array}{l}\text { Index of } \\
\text { success }\end{array}$ \\
\hline $\begin{array}{l}9 \text { Shape } \\
\text { Factors }\end{array}$ & $\begin{array}{l}9 \text { cells with Label } 15 \\
6 \text { cells with Label } 16 \\
1 \text { cell with Label } 11\end{array}$ & $\begin{array}{ll}\text { U9 } & 56,25 \\
\text { U10 } & 37,5 \\
\text { U5 } & 6,25\end{array}$ & 1 \\
\hline $\begin{array}{l}23 \text { Harmonics } \\
\text { Amplitude }\end{array}$ & $\begin{array}{c}10 \text { cells with Label } 15 \\
3 \text { cells with Label } 11 \\
2 \text { cells with Label } 16 \\
1 \text { cell with Label } 17\end{array}$ & $\begin{array}{lc}\text { U9 } & 62,5 \\
\text { U5 } & 18,75 \\
\text { U10 } & 12,5 \\
\text { I3 } & 6,25\end{array}$ & 0.937 \\
\hline $\begin{array}{l}47 \text { Harmonics } \\
\text { Amplitude }\end{array}$ & $\begin{array}{l}8 \text { cells with Label } 15 \\
4 \text { cells with Label } 17 \\
3 \text { cells with Label } 16 \\
1 \text { cell with Label } 18\end{array}$ & $\begin{array}{ll}\text { U9 } & 50 \\
\text { I3 } & 25 \\
\text { U10 } & 18,75 \\
\text { I4 } & 6,25\end{array}$ & 0.687 \\
\hline $\begin{array}{l}24 \text { Harmonics } \\
\text { Amplitude }\end{array}$ & $\begin{array}{l}7 \text { cells with Label } 15 \\
6 \text { cells with Label } 17 \\
3 \text { cells with Label } 16\end{array}$ & $\begin{array}{ll}\text { U9 } & 43,75 \\
\text { I3 } & 37,5 \\
\text { U10 } & 18,75\end{array}$ & 0.625 \\
\hline $\begin{array}{l}\text { Complex } \\
\text { coefficients }\end{array}$ & $\begin{array}{l}12 \text { cells with Label } 15 \\
3 \text { cells with Label } 16 \\
1 \text { cells with Label } 11\end{array}$ & \begin{tabular}{lr} 
U9 & \multicolumn{1}{l}{75} \\
& \\
U10 & 18,75 \\
U5 & 6,25 \\
\end{tabular} & 1 \\
\hline $\begin{array}{l}\text { Hourly Load } \\
\text { profile }\end{array}$ & $\begin{array}{l}9 \text { cells with Label } 13 \\
7 \text { cells with Label } 15\end{array}$ & $\begin{array}{ll}\text { U7 } & 56,25 \\
\text { U9 } & 43,75\end{array}$ & 1 \\
\hline
\end{tabular}

The university A is matched perfectly in the hourly load profile, 9 factors and the 21 harmonics data cases.

2) Small Industry $B$ testing

Three weeks of demand records has been used in this test. The result is presented in table $\mathrm{V}$.

TABLE V

RESULTS OF INDUSTRY B TESTING

\begin{tabular}{|c|c|c|c|}
\hline Training data & Labels identified & $\begin{array}{l}\text { Kind of customer } \\
\text { identified (\%) }\end{array}$ & $\begin{array}{l}\text { Index of } \\
\text { success }\end{array}$ \\
\hline $\begin{array}{l}9 \text { Shape } \\
\text { Factors }\end{array}$ & $\begin{array}{l}15 \text { cells with Label } 17 \\
4 \text { cells with Label } 18 \\
2 \text { cells with Label } 16\end{array}$ & $\begin{array}{lr}\text { I3 } & 71,43 \\
\text { I4 } & 19,05 \\
\text { U10 } & 9,52\end{array}$ & 0,904 \\
\hline $\begin{array}{c}23 \\
\text { Harmonics } \\
\text { Amplitude }\end{array}$ & 21 cells with Label 17 & I3 100 & 1 \\
\hline $\begin{array}{c}47 \\
\text { Harmonics } \\
\text { Amplitude }\end{array}$ & $\begin{array}{l}19 \text { cells with Label } 17 \\
1 \text { cells with Label } 16 \\
1 \text { cells with Label } 18\end{array}$ & $\begin{array}{lr}\text { I3 } & 90,48 \\
\text { U10 } & 4,76 \\
\text { I4 } & 4,76\end{array}$ & 0,952 \\
\hline 24 & 18 cells with Label 17 & I3 85,71 & 1 \\
\hline
\end{tabular}




\begin{tabular}{|c|c|ll|c|}
\hline $\begin{array}{c}\text { Harmonics } \\
\text { Amplitude }\end{array}$ & 3 cells with Label 18 & I4 14,29 & \\
\hline $\begin{array}{c}\text { Complex } \\
\text { coefficients }\end{array}$ & 21 cells with Label 17 & I3 & 100 & 1 \\
\hline $\begin{array}{c}\text { Hourly Load } \\
\text { profile }\end{array}$ & 21 cells with Label 17 & I3 & 100 & 1 \\
\hline
\end{tabular}

\section{3) Residencial C Testing:}

Finally, a month of residential CT measurements is used for testing purposes. The result is shown in table VI.

TABLE VI

RESULTS OF RESIDENTIAL C TESTING

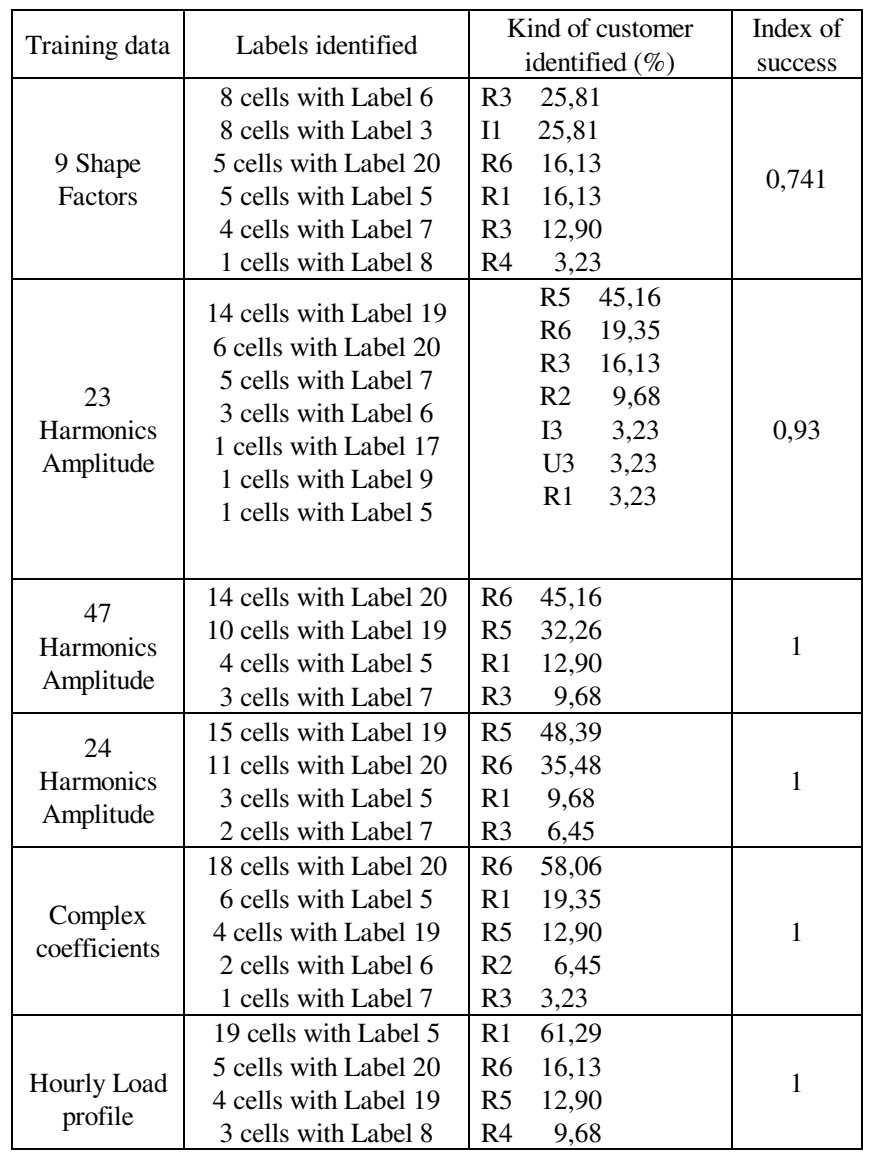

\section{CONCLUSIONS}

The Self-Organizing Maps appears as an interesting tool for electrical customers segmentation, with a broad application field. The network training with the different data input treatment has shown a great classification capacity, joining similar customers in well defined zones. The Hourly Load Profile training provides a clear map with different zones and places similar customers in the same area. The index success ratio shows the identification success capacity. We can conclude that the identification of new customers is of a high quality in both alternatives: hourly load profile and frequency-based indices. However the other treatments are also very good and they obtain a quite high rate of success. So, the electrical market segmentation could be studied using the Self-Organizing maps, training the network with a great quantity of daily load data. Other researching lines and SOM applications are related to electrical tariffs [15] showing if the tariff chosen by the customer is the right one. This position would allow suppliers and clients to determine which is the best rate to pay in each moment among all the available ones in a liberalized market.

\section{REFERENCES}

[1] P.Stephenson, I.Lungu M.Paun, I.Silvas and G.Tupu, "Tariff Development for Consumer Groups in Internal European Electricity Markets", Proc. CIRED 1001, Amsterdam, The Netherlands, June 18-21, 2001, paper 5.3.

[2] T. Kohonen, Self-Organisation and Associative Memory (3rd edn.), Springer-Verlag, Berlin, 1989.

[3] G. Chicco, R. Napoli, F. Piglione, P. Postolache, M.Scutariu, C.Toader, "A Review of Concepts and Techniques for Emergent Customer Categorisation". Available: http://www.telmark.org/2002Sep/24_Chicco.pdf

[4] B. D. Pitt, D. S. Kirschen, "Application of Data Mining Techniques to Load Profiling”, Proc. IEEE PICA'99, Santa Clara, CA, May 16-21, 1999,pp.131-136.

[5] J. A. Jardini, C. M. V. Tohan, M. R. Gouvea, S. U. Ahn, F. M. Figueiredo, "Daily Load Profiles for Residential, Commercial and Industrial Low Voltage Consumers", IEEE Transactions on Power Delivery, Vol. 15, No. 1, January 2000.

[6] C. S. Chen, J. C. Hwang, Y. M. Zzeng, C. W. Huang, M. Y. Cho, "Determination of Customer Load Characteristics by Load Survey System at Taipower", IEEE Transactions on Power Delivery, Vol. 11, No. 3, July 1996.

[7] A. Seppälä, "Statistical Distribution of Customer Load Profiles", IEEE Catalogue No. 95TH8130, 1995.

[8] J. Nazarko, Z.A. Styczynski, "Application of Statistical and Neural Approaches to the Daily Load Profiles Modelling in Power Distribution Systems", Proc. IEEE Transm. and Distrib. Conference, New Orleans, LA, April 11-16,1999, Vol.1, pp.320-325.

[9] G. Chicco, R. Napoli, F. Piglione, "Load Pattern Clustering for ShortTerm Load Forecasting of Anomalous Days", 2001 IEEE Porto Power Tech Conference, 10-13 September, Porto, Portugal.

[10] Bezdek, J. C., "Pattern Recognition with Fuzzy Objective Function Algorithms. Plenum Press, New York, 1981.

[11] DeGruijter, J. J., McBartney, A. B., "A Modified Fuzzy k means for Predictive Classification. In: Bock, H. H.(ed) Classification and Related Methods of Data Analysis. pp. 97-104. Elsevier Science, Amsterdam, 1988.

[12] A. P. Birch, C. S. Özveren, A. T. Sapeluk, "A Generic Load Profiling Technique Using Fuzzy Classification", Metering and Tariff for Energy Supply, 3-5 July 1996, Conference Publication No. 426.

[13] M. Sforma, "Data Mining in a Power Company Customer Database", Electric Power Systems Research, Vol. 5, No.3, September 2000, pp.201209.

[14] R. F. Chang, C. N. Lu, "Load Profile Assignment of Low Voltage Customers for Power Retail Market Applications". IEE Proc. - Gener. Transm. Distrib., Vol. 150, No. 3, May 2003.

[15] G.Chicco, R.Napoli, P.Postolache, M.Scutariu and C.Toader, "Customer Characterisation Options for Improving the Tariff Offer", to appear in the IEEE Transactions on Power Systems.

\section{BIOGRAPHIES}

Sergio Valero was born in Elche, Spain, in 1974. He received the Industrial Engineering degree in 1998, from the Universidad Politécnica de Valencia, Spain.

Currently he is Associate Professor at the Universidad Miguel Hernández de Elche, Spain. His research activities include distribution system analysis, electricity markets, Distributed Energy Resources, Demand-Side Bidding and Neural Network Applications in Power Systems.

Mario Ortiz was born in Murcia, Spain, in 1978. He received the Industrial Engineering degree in 1998, from the Universidad Politécnica de Cartagena, Spain. 
Currently he is Associate Professor at the Universidad Miguel Hernández de Elche, Spain. His research activities include distribution system analysis, electricity markets, Distributed and Renewable Energy Resources, and Neural Network Applications in Power Systems.

Francisco J. García Franco was born in Cartagena, Spain, in 1979. He received the Industrial Engineering degree in Electrical Power Systems in 2003 from the Universidad Politécnica de Cartagena (Spian). Currently he is a research and $\mathrm{Ph} . \mathrm{D}$. student in the Institute of Energy Enginneering at the Universidad Politécnica de Valencia. His research activities include electricity markets, demand modeling, Demand-Side Bidding and electrical customer classification.

Antonio Gabaldón (M'96) was born in Cieza, Spain, in 1964. He received the Industrial Engineering degree in 1988, and the Ph.D. degree from the Universidad Politecnica de Valencia, Spain, in 1991.

Currently he is Full Professor at the Universidad Politécnica de Cartagena, Spain. His research activities include distribution system analysis, electricity markets, demand modeling, Distributed Energy Resources, Demand-Side Bidding and Demand-Responsiveness. 